confounding is ruled out in our later research, where the quality of food was counterbalanced, and essentially the same results were obtained (unpublished study). The lack of sex differences is also observed when VMH-lesioned male and females are tested for reaction to electrical shock on a passive avoidance test or on a timing behavior test (unpublished study).

The basis for the presence of sex differences after $\mathrm{VMH}$ damage in obesity and absence of it in "finickiness" is not clear. It is possible, as suggested by Cox et al, (1969), that sex differences in obesity after VMH damage reflect some differential endocrinological and metabolic effects in males and females. The role of some metabolic factor contributing to the body weight can be inferred from those studies. which have shown that VMH-lesioned rats gain more weight than do control animals of the same caloric intake (Brooks \& Lambert, 1946). The endocrinological factor can be inferred from those studies which report that gonadectomy results in greater weight gains in females but decreased weight gains in males (Kakolewski, Cox, \& Valenstein, 1968). Furthermore, Cox et al (1969) report that male rats castrated and lesioned at the same time exhibit greater weight gains following VMH damage than do noncastrated VMH-lesioned males.

On the basis of these reports, if it is accepted that resultant obesity from VMH damage is at least partly governed by sex-related endocrinological factors, the lack of sex differences in finickiness would imply that finickiness was governed by some separate neural mechanism that is relatively insensitive to sex-related endocrinological factors. The existence of such separate, but overlapping, neural mechanisms for obesity and finickiness within the VMH area has been hypothesized by Graff \& Stellar (1962). If further experimental data sustain their hypothesis, the present finding can be explained within that context, adding that while the neural mechanism for obesity is affected by sex differences, the mechanism for finickiness is not.

\section{REFERENCES}

BROOKS, C. McC., \& LAMBERT, E. F. A study of the effect of limitation of food intake and the method of feeding on the rate of weight gain during hypothalamic obesity in the albino rat. American Joumal of Physiology, 1946, $147,695-707$.

CORBIT, J. D., \& STELLAR, E. Palatability, food intake, and obesity in normal and hyperphagic rats. Journal of Comparative \& Physiological Psychology, 1964, 58, 63-69.

COX, V. C., KAKOLEWSKI, J. W., \& VALENSTEIN, E. S. Ventro medial hypothalamic lesions and changes in body weight and food consumption in male and female rats. Journal of Comparative \&

Physiological Psychology, 1969, 69, 320-326. GOLD, R. M. Hypothalamic hyperph agia: Males get just as fat as females. Journal of Comparative \& Physiological Psychology, 1970, 71, 347-356.

GRAFF, H., \& STELLAR, E. Hyperphagia, obesity, and finickiness. Journal of Comparative \& Physiological Psychology, $1962,55,418-424$.

JACOBS, H. L. Sensory and metabolic regulation of food intake: Thoughts on a dual system regulated by energy balance. VII International Congress of Nutrition at Hamburg, 1966, 2, 3-15.

KAKOLEWSKI, J. W., COX, V. C., \& VALENSTEIN, E. S. Sex differences in body weight changes following gonadectomy of rats. Psychological Reports, 1968, 22, 541-544.

SINGH, D., \& MEYER, D. R. Eating and drinking by rats with lesions of the septum and the ventromedial hypothalamus. Journal of Comparative \& Physiological Psychology,

\title{
Reversal learning in birds as a function of amount of overtraining*
}

\author{
KENNETH A. MATYNIAK, $†$ University of Sussex, Sussex, England \\ and \\ LAURENCE J. STETTNER, Wayne State University, Detroit, Mich. 48202
}

Bobwhite quail were given $80,240,400,640$, or 2,000 overtraining trials after learning a simultaneous visual-pattern discrimination and were then reversed. Reversal performance after all levels of overtraining either did not differ from or was significantly inferior to that of nonovertrained birds. Failure to obtain an ORE was attributed to the fact that overtraining did not reduce responding to an irrelevant position dimension.

Mackintosh (1969) has recently demonstrated that the presence of both a difficult simultaneous visual discrimination and a large reward are sufficient (if not necessary) conditions for the occurrence of the overtraining reversal effect (ORE) in rats. However, using a difficult pattern task and a large magnitude of reward, Matyniak (1970) failed to find any evidence of an ORE in pigeons, indicating that other factors may be important in obtaining the ORE in birds.

A review of avian ORE studies suggests that number of overtraining trials may be a relevant variable. Mackintosh (1965) obtained an ORE in young chicks given 100 overtraining trials, but both Schade \& Bitterman (1965) and Matyniak (1970) found that 200 overtraining trials did not facilitate reversal learning in pigeons. Williams (1967) obtained an ORE in pigeons receiving 500 overlearning trials, but in another experiment with pigeons the same number of trials produced no ORE

*This research was supported in part by NIMH Predoctoral Fellowship 4 F01 MH42453-02 awarded to K. A. Matyniak and in part by NSF Grant GB 5989, L. J. Stettner, principal invertigator. The experiment was performed at Wayne State University.

$\uparrow$ Reprints may be obtained from $K$. A. Matyniak, Laboratory of Experimental Psychology, University of Sussex, Brighton, Sussex, England.
(Marsh \& Johnson, 1968). Finally, Eimas (1967) and Birnbaum (1967) have obtained results suggesting that number of overtraining trials is related to the occurrence of an ORE in rats. Birnbaum, for example, found that 400 overtraining trials facilitated reversal learning, but 200 did not.

The present experiment was designed to determine if the variability of the ORE data in birds could be partially accounted for by differential effects of amount of postcriterion training on speed of reversal learning. Since no single experiment with birds has systematically investigated the effects of varied amounts of overtraining, it was decided to include a number of different levels of overtraining that extended over a wide range.

\section{METHOD}

The Ss were 48 male adult bobwhite quail, Colinus virginianus, approximately 4-6 months old. Upon arrival at the laboratory, Ss were quartered in individual wire cages in which both food and water were continuously available for 1 month prior to the beginning of the experiment.

The apparatus consisted of a rectangular discrimination chamber, $21 \times 11 \times 17$ in., constructed of 1/4-in. Masonite. Three Gerbands transparent circular-response keys, $\frac{1}{4}$ in. in diam, were mounted on the rear wall of the chamber and were $1 \frac{1}{2} \mathrm{in}$. 
Table 1 Acquisition and Reversal Mean Scores

\begin{tabular}{lccccc}
\hline & $\begin{array}{c}\text { Acqui- } \\
\text { sition }\end{array}$ & & \multicolumn{3}{c}{ Reversal } \\
\cline { 2 - 3 } Group & $\begin{array}{c}\text { Total } \\
\text { Errors }\end{array}$ & $\begin{array}{c}\text { Total } \\
\text { Errors }\end{array}$ & $\begin{array}{c}\text { Equal } \\
\text { Choice } \\
\text { Errors }\end{array}$ & $\begin{array}{c}\text { Posi- } \\
\text { tion } \\
\text { Blocks }\end{array}$ \\
\hline OT 0 & 40.4 & 78.5 & 36.7 & 6.0 \\
OT 80 & 37.8 & 99.8 & 43.4 & 6.5 \\
OT 240 & 37.9 & 121.0 & 40.3 & 7.3 \\
OT 400 & 45.5 & 113.6 & 62.1 & 9.0 \\
OT 640 & 32.5 & 137.2 & 71.5 & 7.1 \\
OT 2000 & 40.0 & 162.1 & 89.4 & 10.3 \\
\hline
\end{tabular}

apart horizontally and $7 \mathrm{in.}$ above the wire floor. Grason-Stadler multiple-display stimulus projectors were located directly behind each response key. Stimuli used during discrimination training consisted of three white stripes, $1 / 8$ in. wide, set on a black background, one stimulus oriented horizontally and the other vertically. The pretraining stimulus was a 3 -in.-diam white circle. Reinforcement (Purina Game Bird Chow) was administered by a standard solenoid-operated grain hopper mounted 2 in. above the floor, midway between the left and right response keys and directly below the center key. The apparatus was constantly illuminated by fluorescent bulbs located on the ceiling of the experimental room.

Programming of all experimental contingencies was completely automated and consisted of standard relays, stepping switches, counters, and timers located in an adjacent room. Data were recorded by an Esterline Argus multiple-event recorder.

Prior to the start of pretraining, Ss were reduced to $85 \%$ of their free-feeding body weights over a 2-week period. Pretraining consisted of shaping $S$ to peck at the white circle when projected on the center key, the other two keys being covered. All Ss were given 50 reinforced trials of center-key responding, a trial consisting of: (1) the appearance of the white circle on the center key, (2) a response to the key which turned off the stimulus, (3) immediate reinforcement of 5-sec access to grain following a response. The circle was projected at random intertrial intervals of 15,20, and $25 \mathrm{sec}$ and remained projected until $S$ responded.

Following pretraining, Ss were assigned randomly to one of six groups prior to two-key discrimination training. All groups learned the horizontal-vertical simultaneous discrimination, the center key being covered. Following acquisition, the control group (OT $O$ ) was immediately given a reversal; i.e., the reinforced stimulus value during acquisition was no longer reinforced and the previous $\mathrm{S}-$ was now reinforced. The five experimental groups received $80,240,400,640$, or 2,000 overtraining trials, respectively, followed by a reversal. Half the Ss in each group learned the initial discrimination with horizontal stripes reinforced and half with vertical. Stimuli were presented according to Gellerman sequence, and intertrial intervals varied between 15 and $25 \mathrm{sec}$. A response to either key terminated the stimuli, with a correct choice resulting in 5-sec access to food. Ss were 22-24 h deprived and were given daily 80-trial sessions. Learning criterion for both acquisition and reversal was set at 18 out of $20(90 \%)$ correct responses in two consecutive 10-trial blocks. A noncorrection procedure was used throughout.

\section{RESULTS}

As can be seen from the total error scores in Table 1, acquisition and reversal of the pattern discrimination was quite difficult for all groups. No significant differences were found for errors made during acquisition, an analysis of variance yielding an $F$ of $1.52(\mathrm{df}=5 / 42, \mathrm{p}>.2)$. Difficulty in learning the reversal, however, increased as a function of overtraining, a sjgnificant $F$ of $2.63(\mathrm{df}=5 / 42, \mathrm{p}<.05)$ being obtained for total errors to reversal criterion. A Newman-Keuls test further indicated that Groups OT 640 and OT 2000 were inferior to the control group $(p<.05)$, but no other group comparisons were significant.

Two other measures of reversal performance were examined in order to more precisely determine the manner in which overtrained Ss differed from controls. The errors-to-equal-choice measure in Table 1 reflects the difficulty of extinguishing responses to the former positive stimulus during the reversal. The mean figures shown represent the sum of reversal errors until a 10-trial block was attained in which responses were equally divided between both stimulus values. Greater amounts of overtraining significantly increased resistance to extinction of responses to the former $\mathrm{S}+$ $(F=2.48, \quad$ df $=5 / 42, \quad p<.05), \quad$ a Newman-Keuls analysis again indicating that Groups OT 640 and OT 2000 extinguished significantly more slowly than did controls $(p<.05)$.

Table 1 also shows the mean number of 10-trial reversal blocks in which $\mathrm{S}$ responded eight or more times to either the left or the right response key, indicating strong position biases. It can be seen that overtrained $S$ s tended to revert to position responding more than did controls, but this difference was not significant $(F<1)$.

\section{DISCUSSION}

The present experiment confirms the results of Schade \& Bitterman (1965) and Matyniak (1970) in that overtraining failed to facilitate reversal learning of a visual discrimination in birds. Ss given moderate amounts of overtraining, up to 400 trials, did not differ from nonovertrained $S$ s in rate of learning the reversal, whereas extended amounts of overtraining retarded reversal performance. It thus does not appear probable that absolute number of postcriterion trials determines the occurrence of an ORE in birds.

A closer analysis of the present results does, however, indicate a possible explanation for the failure to obtain an ORE. Most of the rat ORE studies (cf. Mackintosh, 1969) have found that overtraining increases resistance to extinction of responses to the former $\mathrm{S}+$ during reversal, independent of the occurrence of an ORE, suggesting that when overtraining facilitates reversal performance, it does so in spite of its effect on extinction. The present study demonstrates a similar relationship between overtraining and resistance to extinction in birds. Overtraining, however, did not appear to decrease responding to an irrelevant stimulus dimension (i.e., position) during reversal. There was, in fact, a small trend for Ss given increased amounts of overtraining to revert to this response bias more extensively. In those studies which have obtained an ORE in the rat, the most potent effect of overtraining has been to reduce the proportion of time Ss spend responding to irrelevant stimulus dimensions, particularly spatial position. It thus appears probable that the failure of overtraining to facilitate pattern reversal in the present experiment can be attributed to this factor.

\section{REFERENCES}

BIRNBAUM, I. M. Discrimination reversal, extinction, and acquisition after different amounts of overtraining. American Journal of Psychology, 1967, 80, 363-369.

EIMAS, P. D. Overtraining and reversal discrimination learning in rats. Psychological Record, 1967, 17, 239-248.

MACKINTOSH, N. J. Overtraining, extinction, and reversal in rats and chicks. Joumal of Comparative \& Physiological Psychology, 1965, 59, 31-36.

MACKINTOSH, N. J. Further analysis of the overtraining reversal effect. Journal of Comparative \& Physiological Psychology, 1969, 67(2, Pt. 2).

MARSH, G., \& JOHNSON, R. The effect of irrelevant cues and overtraining on discrimination reversal in the pigeon. Psychonomic Science, 1968, 12, 321-322.

MATYNIAK, K. A: Reversal and nonreversal shift learning in pigeons as a function of problem difficulty, magnitude of reward and overtraining. Unpublished doctoral dissertation, 1970.

SCHADE, A. F., \& BITTERMAN, M. E. The relative difficulty of reversal and dimensional shifting as a function of overlearning. Psychonomic Science, 1965, 3, 283-284.

WILLIAMS, D. I. The overtraining reversal effect in the pigeon. Psychonomic Science, 1967, 7 261-262. 